surgical trainee decision making and theatre experience are an essential part of training and further attempts to dilute the clinical workload will produce surgeons with scant or inadequate experience, particularly in emergency surgery. Continuity of care is essential for both the patient and the attending doctor, particularly in early postoperative patients and in critical care. Time off after a night on call is impracticable.

Shift systems may be practicable in the casualty department, where there is little continuity of inpatient care, but are not suited to most surgical specialties. The financial implications of increased teams of doctors working reduced hours do not bear thinking about, particularly as the system of care will be inferior to the existing system.

I am concerned that a national campaign can be launched without consulting the profession as a whole (none of the doctors I have spoken to in Birmingham were previously aware of this campaign) and that publicly this may be seen as a current attitude of the whole profession.

K M PORTER Birmingham Accident Department, Birmingham B15 INA

$*^{* *}$ A motion at this year's Hospital Junior Staff Conference calling for the setting of a maximum working week of 60 hours for junior doctors was defeated (see 2 June, p 1919).—ED, BMF.

\section{Patients last?}

SIR,-Many congratulations to Dr Julian Leigh and his colleagues from the Royal Surrey County Hospital for presenting publicly such a detailed analysis of the plight of the acute sector in a peripheral district of one of the four London based regional health authorities ( 8 June, $p$ 1758). We are sure any objective observer will be startled to learn of the predicament in which Guildford now finds itself.

Guildford, however, is by no means unique. The Canterbury and Thanet health district is also being faced with massive cuts in the acute sector and only last week 43 beds at the Kent and Canterbury Hospital and one operating list a day were closed as well as ward closures at the Royal Sea Bathing Hospital, Margate. The immediate effects of these cuts, at a conservative estimate, will be a loss of at least 1000 operations a year. We have produced figures in much the same way as Guildford and are convinced that the future looks bleak. Both Canterbury and Guildford have multidistrict specialties such as radiotherapy, and the concentration of specialist skill does have a snowball effect in attracting more complex work to the hospital which is inadequately funded. Another similarity is that they are both peripheral districts in regions that have been severely affected by the RAWP redistribution of money.

We are not aware of the funding details of the South West Thames Regional Health Authority but in the South East Thames region Canterbury and Thanet Health district and other peripheral districts are currently being funded at only $86 \%$ of the RAWP target figure. We have in the region three teaching hospitals, which are being funded at grossly over their RAWP allocations-in one case to the tune of nearly $140 \%$. This overfunding suems to be being made at the expense of peripheral districts because of the fixed cash limits already placed on the regional health authority.

Teaching hospital districts quite correctly point out that they have been forced to make massive cuts already and are unable to reach their targets immediately. It would seem that only two alternative responses to their predicament are tenable. Firstly, they can in fact meet their RAWP targets immediately and if so should be forced to do so, thus releasing money to the other districts in the region, or, secondly, the level and timing of the cuts to the teaching health authorities are inappropriate. If so it seems quite wrong of central government to insist on trimming the regional health authority's budget at either the level or rate presently involved. Central government should be made aware of this problem, and the effects on peripheral districts such as Guildford and Canterbury should be pointed out. The article from Guildford seems to achieve this most convincingly.

The government claims that the health service is expanding. The Guildford study has revealed eloquently the situation occurring in peripheral health districts - that totally unreasonable cuts are being made and that far from an improvement in the health services the very greatest deterioration can be expected.

R E C Collins M J GOGGIN

Kent and Canterbury Hospital Canterbury CT1 3 NG

British and American spellings of technical words

SIR,-Dr J L Burton's plea to use American spelling instead of English in British medical publications is redolent of the request made by one of his predecessors when he was editor of the British Fournal of Dermatology - to avoid using the third person passive voice in medical writing in the interests of clarity. In both cases the changes lead to a style of medical writing which is unattractive and inconsistent. Let me illustrate this with a sentence in the current issue of the British fournal of Dermatology: "A pooled sample of keratin was obtained from 40 non-diabetic patients" might become, "I took bits of keratin from non-diabetic patients and mixed them." The meaning of the latter sentence is clear but the style would become tedious to many readers after several pages.

In seeking consistency Dr Burton overlooks the effect that confining his suggestion to a change in spelling of certain words-haematology to hematology, for example-introduces greater inconsistencies to the general style of a paper. Most readers are aware that the American style of writing English is quite different from the British English advocated by $\mathrm{H}$ W Fowler, Sir Ernest Gowers, and others. Are we then to change our vocabulary and habits of construction to the American style in the interests of consistency and easier comprehension by the American reader?

For a British author or editor to attempt to write American English is as difficult as it is for a Dane or a Japanese author to write a paper whose style is acceptable for publication without alteration, as most editors know. Fowler writes, "The English and American language and literature are both good things; but they are better apart than mixed."

Let us continue to anglicise the spelling of American papers submitted to British journals and let American editors "correct" the spelling in our papers. That British journals are read in many other countries is an unconvincing and prosaic argument, reminiscent of past attempts to make us communicate in Esperanto.

W A D GRIFFITHS

Clinical and Experimental Dermatology,

St John's Hospital for Diseases of the Skin,

London WC2H 7B J

1 Fowler HW, Fowler FG. The King's English. 3rd ed. Oxford: OUP, 1931
SIR,--Dr J L Burton (15 June, p 1828) may or may not find support for his challenge to you to lead the way with American spelling of scientific and technical terms in British journals. I for one would not support him, but I doubt whether anyone would if he chooses as his example the word fetus/ foetus. Fetus is not the American spelling but is the etymologically correct English form. Foetus, albeit hallowed by long misuse, is incorrect.

Harlow, Essex CM20 2RP

R N PALMER

\section{Points}

\section{Does gymnastics damage the spine?}

Dr J David WatTs (Dundonald, Ayrshire KA2 9HE) writes: In reviewing Principles of Sports Medicine Mr I P Stewart (25 May, p 1583) notes that the book "does not tackle the long term consequences of the gymnastic contortions of the adolescent spine." This accusation is often made against gymnastics and there is rarely any attempt to justify it. Gymnastics may be an unusual hobby for a GP, but personal experience suggests that there are no important long term consequences to the adolescent spine from gymnastics which is properly taught in the absence of pre-existing disease or malformation. Today's judges are taught to prefer a straight back whenever possible and to award deductions when a straight shape is not achieved. Coaches are taught that those activities which require hyperextension, which are all derived from bending over backwards to touch the floor, should be produced by increasing the range of movement in the shoulders and not the lower back. If $\mathrm{Mr}$ Stewart has hard evidence to show that gymnastics has long term dangers then it would be helpful if it could be published. In the meantime my experience of working with large numbers of young girls at the bottom end of the sport is that it is no more hazardous than many other activities associated with normal living and that of the injuries sustained spinal problems are few and not important.

\section{Haematuria in patients with haemostatic} defects

Dr S K SINHA (North Western Regional Perinatal Centre, St Mary's Hospital, Manchester M13 0JH writes: Dr I A Greer and colleagues (1 June, p 1648 report a case of haematuria due to renal carcinoma in patient with von Willebrand's disease. I would like 10 draw attention to another patient, whom I cared for in a previous post, whose haematuria was wrongly attributed to her pre-existing haemostatic defect. A 9 year old girl presented with purpuric lesions over the whole of the body surface and mucus membrane after a presumed viral upper respiratory tract infection. A diagnosis of idiopathic thrombocytopenic purpura was confirmed on examination of peripheral blood and bone marrow. During her hospital stay she was given a blood transfusion because of concomitan anaemia. Following this she started passing red urine and complained of vague pain in her abdominal flanks. These symptoms were at first attributed to her very low platelet count of $<10 \times 10^{9} / 1$ until an error of cross matching of the transfused blood was notified by the laboratory the following morning. The symptoms subsided, however, without any therapeutic intervention and she did not develop any major sequelae of ntravascular haemolysis resulting from incompatible blood transfusion.

\section{Correction}

HTLV-III, haemophilia, and blood transfusion

We regret that an error occurred in this letter by Professor A L Bloom and others (22 June, p 1901). The last sentence of the fourth paragraph should have read: "The risk of HTLV-III infection in such patients could now be as high as one in 200 in some areas of Britain," not one in 20. 